\title{
Mikrostruktura i właściwości mechaniczne natryskanych plazmowo powłok $\mathrm{ZrO}_{2}-8 \mathrm{Y}_{2} \mathrm{O}_{3}$
}

\author{
Microstructure and mechanical properties \\ of plasma sprayed $\mathrm{ZrO}_{2}-8 \mathrm{Y}_{2} \mathrm{O}_{3}$ coatings
}

\section{Streszczenie}

Materiały nanostrukturalne $\mathrm{z}$ powodu ich bardzo dobrych mechanicznych i fizycznych właściwości są coraz szerzej wykorzystywane w różnych zastosowaniach. Jedną z możliwości nakładania powłok nanostrukturalnych jest natryskiwanie plazmowe. W pracy przedstawiono badania mikrostruktury i właściwości mechanicznych powłok $\mathrm{ZrO}_{2}-8 \mathrm{Y}_{2} \mathrm{O}_{3}$. Powłoki zostały natryskane $\mathrm{z}$ zawiesiny przy użyciu systemu do natryskiwania plazmowego Axial III oraz z proszku Metco 204 NS stosując system Plancer PN120. Powłoka osadzona z proszku posiadała typową lamellarną strukturę, natomiast powłoka natryskana z zawiesiny miała zróżnicowaną mikrostrukturę, w której nanoziarna otoczone były przez całkowicie stopiony materiał powłokowy. Przeprowadzone badania nanoindentacji powłok (twardość i moduł Younga) wykazały zróżnicowanie wartości w zależności od badanego obszaru powłoki (strefa całkowicie lub częściowo stopiona).

Słowa kluczowe: natryskiwanie plazmowe, zawiesina, $\mathrm{ZrO}_{2}-8 \mathrm{Y}_{2} \mathrm{O}_{3}$

\begin{abstract}
Nanostructured materials are of particular scientific interest because of their physical and mechanical properties, which are superior compare to those of conventional materials. They are more widely used in various industrial applications mainly due to decreasing production costs. The work is concerned with a study of microstructure and mechanical properties of $\mathrm{ZrO}_{2}-8 \mathrm{Y}_{2} \mathrm{O}_{3}$ coatings. The coatings were sprayed by means of a SPS (Axial III) and APS (Plancer 120, Metco 204 NS). In opposite to conventional lamellar APS microstructure, SPS coatings showed two-zone microstructure which consisted of nano-particles surrounded by fully molten areas. Nanoindentation tests showed a distribution of the mechanical properties (hardness and Young's modulus) which is related to the different areas (molten and partially molten) present in the coatings.
\end{abstract}

Keywords: plasma spraying, suspension, $\mathrm{ZrO}_{2}-8 \mathrm{Y}_{2} \mathrm{O}_{3}$

\section{Wstęp}

Inżynieria powierzchni to obszar w którym stale poszukuje się nowych rozwiązań oraz modyfikuje już istniejące technologie. Obejmują one zastosowanie nowych materiałów oraz wykorzystanie najnowszych technik modyfikacji warstwy wierzchniej i osadzania powłok. Obecnie stosowanych jest wiele technologii pozwalających znacznie polepszyć właściwości warstwy wierzchniej $[1,2]$. Wiele uwagi poświęca się zwłaszcza możliwościom zastosowania nanomateriałów z powodu ich lepszych mechanicznych i fizycznych właściwości. Jednocześnie taka sytuacja spowodowała intensyfikację badań nad wykorzystaniem nanomateriałów w procesach natryskiwania cieplnego, co pozwoliło na otrzymywanie całkiem nowej klasy powłok o budowie nanostrukturalnej [3]. Takie powłoki posiadają znacznie lepsze właściwości niż natryskane z materiałów nanostrukturalnych [4].

Wielkość cząstek o rozmiarach nanometrycznych i submikronowych stwarza trudności technologiczne z bezpośrednim wprowadzeniem ich w strumień gazów. Dlatego też opracowano rozwiązania, które umożliwiły zastosowanie takich materiałów w procesach natryskiwania cieplnego. Pierwsza metoda to wytwarzanie proszków o typowej dla tej technologii granulacji w zakresie od 15 do $50 \mu \mathrm{m}$, których ziarna zbudowane są z nanokryształów [5]. Inne rozwiązanie to wprowadzenie nanostrukturalnych proszków w postaci zawiesiny w naddźwiękowy strumień gazów - High Velocity Suspension Flame Spraying (HVSFS) lub strumień plazmy - Suspension Plasma Spraying (SPS). Obydwie metody umożliwiają otrzymywanie nanostrukturalnych powłok z różnych

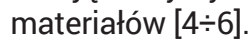

Szczególnie interesujące są powłoki z tlenku cyrkonu stabilizowanego tlenkiem itru, które są szeroko stosowane jako bariery cieplne na elementach silników odrzutowych.

Celem przeprowadzonej pracy były badania mikrostruktury i właściwości mechanicznych powłok $\mathrm{ZrO}_{2}-8 \mathrm{Y}_{2} \mathrm{O}_{3}$ natryskanych plazmowo z zawiesiny $\mathrm{i}$ konwencjonalnego proszku.

Mgr inż. Krzysztof Sokołowski, dr hab. inż.Wojciech Żórawski - Politechnika Świętokrzyska, dr inż. Anna Góral - Instytut Metalurgii i Inżynierii Materiałowej PAN, dr inż. Medard Makrenek- Politechnika Świętokrzyska. 


\section{Metodyka badań}

Proces natryskiwania plazmowego zawiesin przeprowadzono przy użyciu zrobotyzowanego systemu do natryskiwania plazmowego Axial III (Northwest Mettech Corp) z osiowym podawaniem zawiesiny (rys. 1). Plazmotron, zintegrowany z podajnikiem zawiesin NanoFeed 350 umożliwia natryskiwanie ultra drobnych proszków oraz wytwarzanie

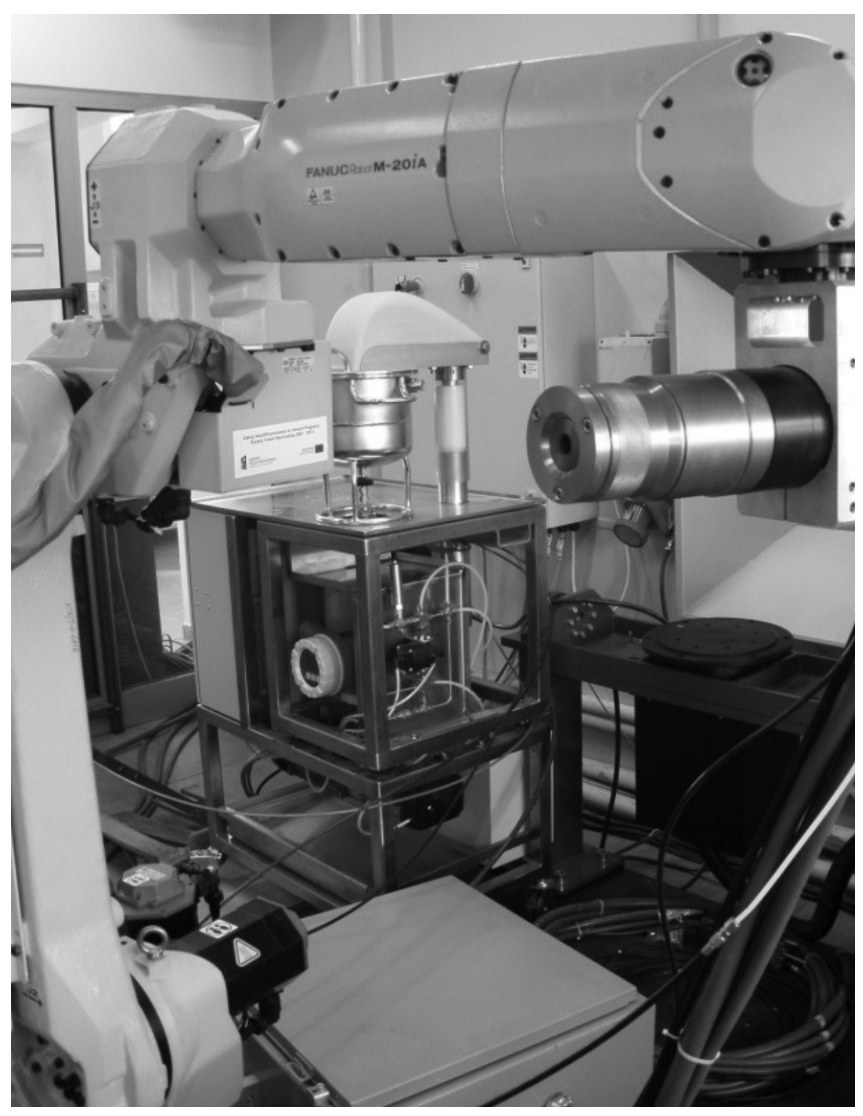

Rys. 1. Zrobotyzowany system do natrysku plazmowego AXIAL III Fig. 1. Robotized system for plasma spraying AXIAL III

Tablica I. Parametry natryskiwania plazmowego zawiesiny Table I. Parameters of plasma spraying of $\mathrm{ZrO}_{2}-8 \mathrm{Y}_{2} \mathrm{O}_{3}$ suspension

\begin{tabular}{|c|c|}
\hline Parametr & Wartość \\
\hline $\begin{array}{c}\text { Wydatek gazów plazmotwórczych, } \\
\text { l/min }\end{array}$ & 245 \\
\hline $\begin{array}{c}\text { Skład gazów plazmotwórczych, } \% \\
\text { Natężenie prądu, A }\end{array}$ & $240 \mathrm{Ar} / 15 \mathrm{~N}_{2} / 20 \mathrm{H}_{2}$ \\
\hline Prędkość robota, $\mathrm{m} / \mathrm{s}$ & 2 \\
\hline Odległość natryskiwania, $\mathrm{mm}$ & 50 \\
\hline
\end{tabular}

Tablica II. Parametry natryskiwania plazmowego proszku $\mathrm{ZrO}_{2}-8 \mathrm{Y}_{2} \mathrm{O}_{3}$ Table II. Parameters of plasma spraying of $\mathrm{ZrO}_{2}-8 \mathrm{Y}_{2} \mathrm{O}_{3}$ powder

\begin{tabular}{|c|c|}
\hline Parametr & Wartość \\
\hline Prąd, A & 600 \\
\hline Napięcie, V & 60 \\
\hline Ciśnienie, MPa & 0,7 \\
\hline Odległość natryskiwania, mm & 100 \\
\hline Prędkość podawania proszku, g/min & 45 \\
\hline
\end{tabular}

nanostrukturalnych powłok. Parametry natryskiwania plazmowego zawiesiny $\mathrm{ZrO}_{2}-8 \mathrm{Y}_{2} \mathrm{O}_{3}$ są przedstawione w tablicy I. Powłoki z konwencjonalnego proszku natryskano plazmotronem Plancer PN 120 z promieniowym wprowadzeniem materiału powłokowego (tabl. II). Powłoki do badań metalograficznych natryskano na próbki z blachy ze stali nierdzewnej o wymiarach $50 \times 25 \times 5 \mathrm{~mm}$. Przed natryskiem próbki zostały odtłuszczone i poddane obróbce strumieniowo-ściernej elektrokorundem EB-30 przy ciśnieniu 0,5 MPa. Grubość natryskanych powłok wynosiła $0.5 \mathrm{~mm}$. Do badania struktury i składu chemicznego powłok zastosowano mikroskop skaningowy JSM-5400 z mikrosondą ISIS 300 Oxford (EDS) oraz SEM FEI Nova ${ }^{\mathrm{TM}}$ NanoSEM 200 and TEM Philips CM20 z EDAX EDX. Badania właściwości mikromechanicznych powłok przeprowadzono przy użyciu testera Nanovea z wgłębnikiem Berkovicha. Analiza topografii powierzchni natryskanych powłok została przeprowadzona przy użyciu profilometru Talysurf CCI-Lite 3D [7].

\section{Wyniki badań i dyskusja}

\section{Charakterystyka proszków $\mathrm{ZrO}_{2}-8 \mathrm{Y}_{2} \mathrm{O}_{3}$}

Do natryskiwania powłok zastosowano dwa rodzaje materiału powłokowego $\mathrm{ZrO}_{2}-8 \mathrm{Y}_{2} \mathrm{O}_{3}$; wodną zawiesinę zawierającą $8 \%$ wt. tlenku cyrkonu stabilizowanego tlenkiem itru o submikronowych wymiarach ziaren (rys. 2a) dostarczoną przez firmę Northwest Mettech Corp. oraz proszek $\mathrm{ZrO}_{2}-8 \mathrm{Y}_{2} \mathrm{O}_{3}$ (Metco 204 NS) o zakresie granulacji $-125+11 \mu \mathrm{m}$ (rys $2 \mathrm{~b}$ ).
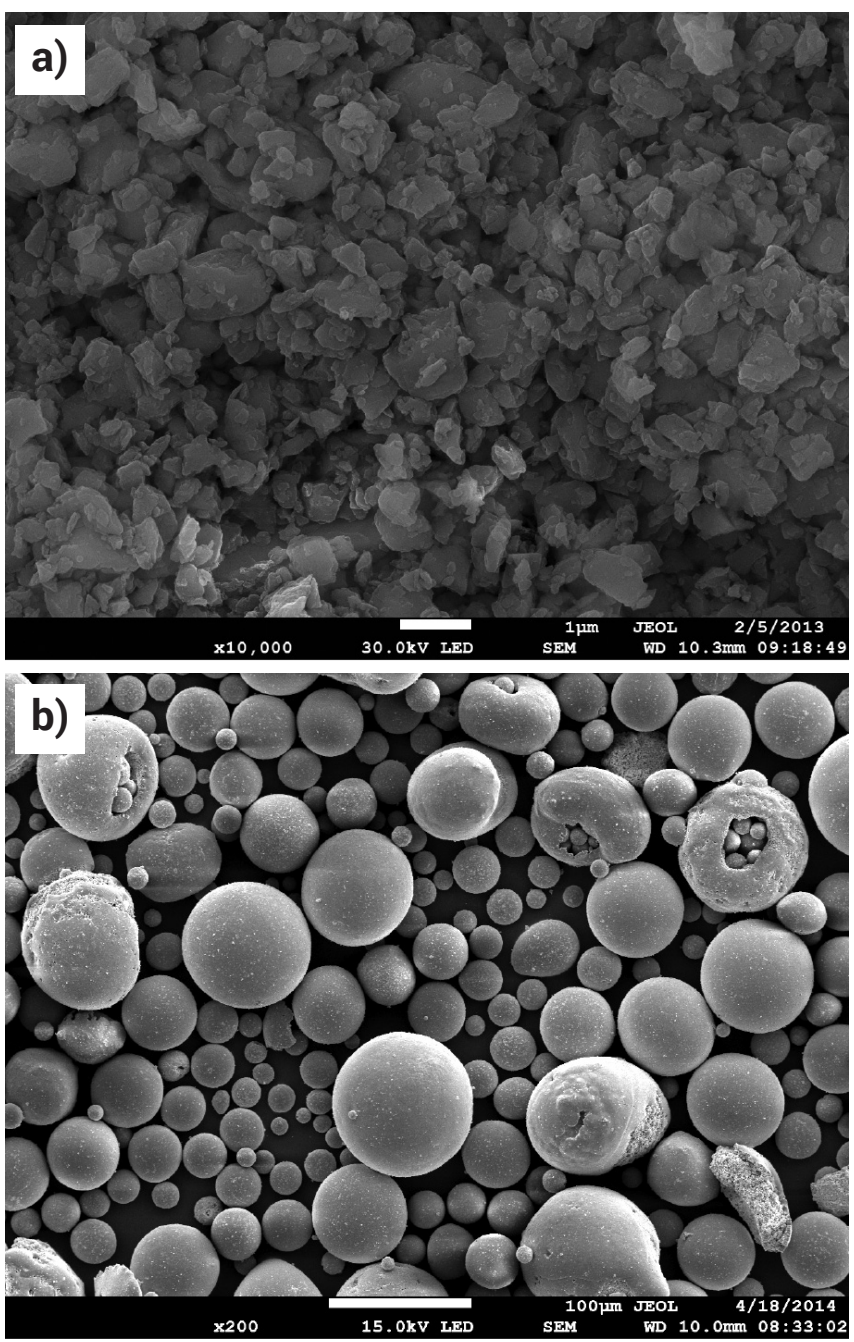

Rys. 2. Morfologia materiału powłokowego $\mathrm{ZrO}_{2}-8 \mathrm{Y}_{2} \mathrm{O}_{3}$ : a) nanometryczne i submikronowe ziarna w zawiesinie, b) ziarna proszku Metco 204 NS

Fig. 2. Morphology of $\mathrm{ZrO}_{2}-8 \mathrm{Y}_{2} \mathrm{O}_{3}$ coating materials: a) nano- and submicron grains in suspension, b) grains of powder Metco 204 NS 


\section{Charakterystyka powłok $\mathrm{ZrO}_{2}-8 \mathrm{Y}_{2} \mathrm{O}_{3}$}

Mikrostruktura powłoki natryskanej plazmowo z zawiesin jest przedstawiona na rysunku $3 \mathrm{a}$ i b. Wprowadzona centralnie w strumień plazmy zawiesina ziaren $\mathrm{ZrO}_{2}-8 \mathrm{Y}_{2} \mathrm{O}_{3}$ podczas natryskiwania ulega rozpyleniu. Następnie tworzy kropelki, które zawierają submikronowe ziarna proszku. Po odparowaniu wody i uderzeniu w powierzchnię ulegają one całkowitemu lub częściowemu odkształceniu tworząc powłokę (rys. 3a). Mikrostruktura powłoki natryskanej plazmowo z zawiesin jest ukształtowana z bardzo cienkich, przylegających do siebie lameli, pomiędzy którymi granice są niewidoczne. Powłoka jest pozbawiona pęknięć, które zwykle występują w powłokach ceramicznych natryskanych plazmowo.
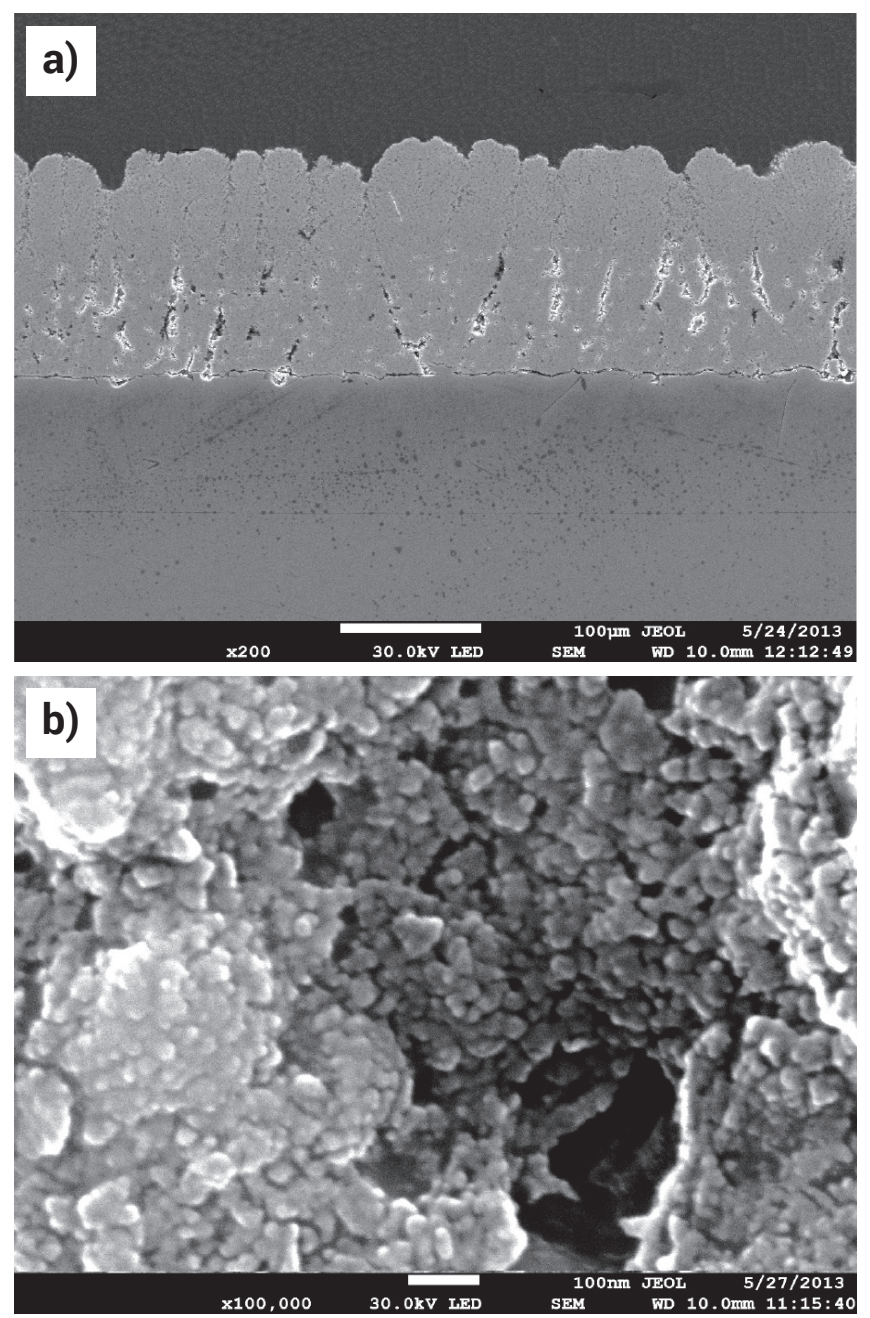

Rys. 3. Mikrostruktura powłoki $\mathrm{ZrO}_{2}-8 \mathrm{Y}_{2} \mathrm{O}_{3}$ natryskanej plazmowo z zawiesin: a) powiększenie 200x, b) powiększenie 100000x

Fig. 3. Microstructure of $\mathrm{ZrO}_{2}-8 \mathrm{Y}_{2} \mathrm{O}_{3}$ coating plasma sprayed from suspension: a) magnification $200 \mathrm{x}$, b) magnification $100000 \mathrm{x}$

Mikrostruktura natryskanej plazmowo powłoki z zawiesin widoczna jest dopiero pod znacznie większym powiększeniem (rys. 3b). Jest to mikrostruktura bi-modalna, w skład której wchodzą obszary całkowicie przetopione oraz obszary, które nie uległy całkowitemu przetopieniu i zawierają połączone ze sobą nanoziarna proszku $\mathrm{ZrO}_{2}-8 \mathrm{Y}_{2} \mathrm{O}_{3}$. Taka powłoka posiada strukturę kolumnową, która w zasadniczy sposób różni się od budowy powłok natryskanych z proszków konwencjonalnych, ponieważ nie jest widoczna typowa mikrostruktura lamelarna z widocznymi granicami pomiędzy poszczególnymi lamelami (rys. 4a i b).

Obraz topografii powierzchni natryskanej plazmowo powłoki $\mathrm{ZrO}_{2}-8 \mathrm{Y}_{2} \mathrm{O}_{3} \mathrm{z}$ zawiesiny oraz proszku jest pokazany na rys. $5 \mathrm{a}$ i $5 \mathrm{~b}$ a ich parametry przedstawione $\mathrm{w}$ tablicy III.
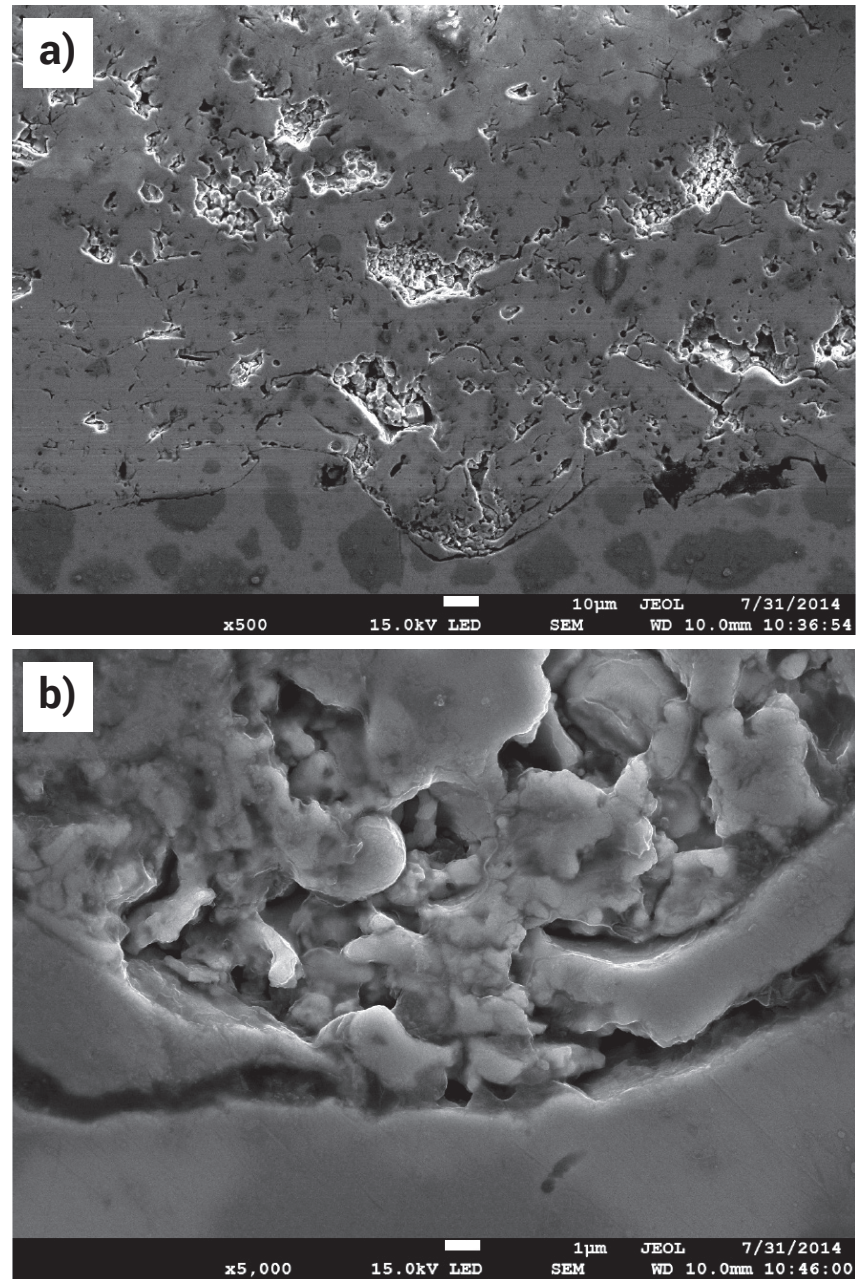

Rys. 4. Mikrostruktura powłoki $\mathrm{ZrO}_{2}-\mathrm{Y}_{2} \mathrm{O}_{3}$ natryskanej plazmowo z proszku Metco 204 NS: a) powiększenie 500x, b) powiększenie 5000x Fig. 4. Microstructure of $\mathrm{ZrO}_{2}-\mathrm{Y}_{2} \mathrm{O}_{3}$ coating plasma sprayed from Metco 204 NS powder. a) magnification 500x, b) magnification 5000x

a)

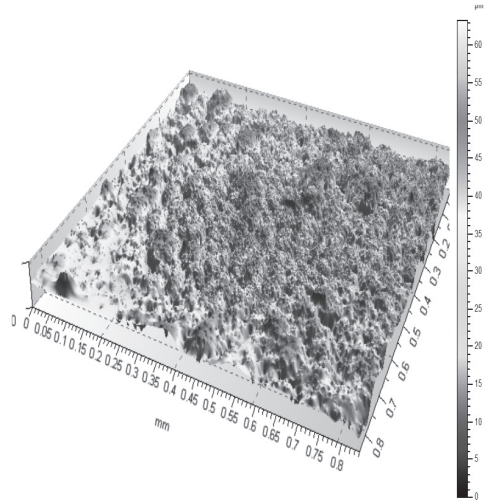

b)

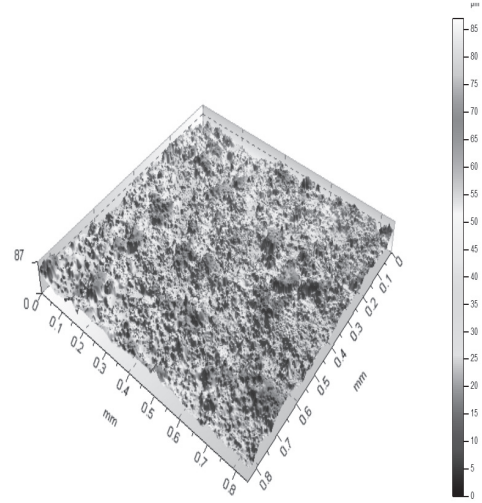

Rys. 5. Topografia powierzchni powłoki $\mathrm{ZrO}_{2}-8 \mathrm{Y}_{2} \mathrm{O}_{3}$ natryskanej plazmonowo: a) z zawiesiny, b) z proszku Metco 204NS

Fig. 5. Surface topography of $\mathrm{ZrO}_{2}-8 \mathrm{Y}_{2} \mathrm{O}_{3}$ coating plasma sprayed from: a) suspension, b) Metco 204NS powder 
Tablica III. Parametry topografii powłoki $\mathrm{ZrO}_{2}-8 \mathrm{Y}_{2} \mathrm{O}_{3}$ natryskanej plazmowo z zawiesiny

Table III. Parameters of topography of $\mathrm{ZrO}_{2}-8 \mathrm{Y}_{2} \mathrm{O}_{3}$ coating plasma sprayed from suspension

\begin{tabular}{|c|c|c|}
\hline \multirow{2}{*}{ Parametr } & \multicolumn{2}{|c|}{ Powierzchnia powłoki $\mathrm{ZrO}_{2}-8 \mathrm{Y}_{2} \mathrm{O}_{3}$ po natrysku, $\mu \mathrm{m}$} \\
\cline { 2 - 3 } & Zawiesina & Proszek \\
\hline $\mathrm{S}_{\mathrm{a}}$ & 5,28 & 7,57 \\
\hline $\mathrm{S}_{\mathrm{q}}$ & 6,92 & 9,55 \\
\hline $\mathrm{S}_{\mathrm{sk}}$ & $-0,28$ & 0,21 \\
\hline $\mathrm{S}_{\mathrm{ku}}$ & 3,894 & 3,131 \\
\hline $\mathrm{S}_{\mathrm{p}}$ & 28,95 & 39,49 \\
\hline $\mathrm{S}_{\mathrm{v}}$ & 34,35 & 47,53 \\
\hline $\mathrm{S}_{\mathrm{z}}$ & 63,30 & 87,02 \\
\hline
\end{tabular}

Parametry topografii powierzchni natryskanej plazmowo z zawiesiny powłoki $\mathrm{ZrO}_{2}-8 \mathrm{Y}_{2} \mathrm{O}_{3}$ są odzwierciedleniem procesów zachodzących w strumieniu plazmy. Pod wpływem sił aerodynamicznych strumienia plazmy zawiesina ulega rozpadowi na krople, z których następuje odparowanie wody, a następnie spiekanie drobnych ziaren $\mathrm{ZrO}_{2}-8 \mathrm{Y}_{2} \mathrm{O}_{3}$. $\mathrm{W}$ następnym etapie submikronowe oraz nanometryczne ziarna oraz ich aglomeraty ulegają stopieniu, przy jednoczesnym procesie parowania, który występuje na ich powierzchni. Część cząstek, która zawiera dużą ilość aglomeratów, nie ulega całkowitemu odkształceniu w momencie uderzenia, co jest dobrze widoczne na powierzchni powłoki (rys. 5a) tworząc powłokę o znacznie mniejszej średniej arytmetycznej wysokości powierzchni $\left(S_{a}=5,28\right)$ niż w przypadku powłoki natryskanej z proszku konwencjonalnego $\left(S_{a}=7,57\right)$.

Wyniki badań indentacji są przedstawione na rysunku 6.

W tablicy IV przedstawione są wyniki pomiarów właściwości mechanicznych powłoki natryskanej plazmowo z zawiesiny oraz proszku $\mathrm{ZrO}_{2}-8 \mathrm{Y}_{2} \mathrm{O}_{3}$. a)

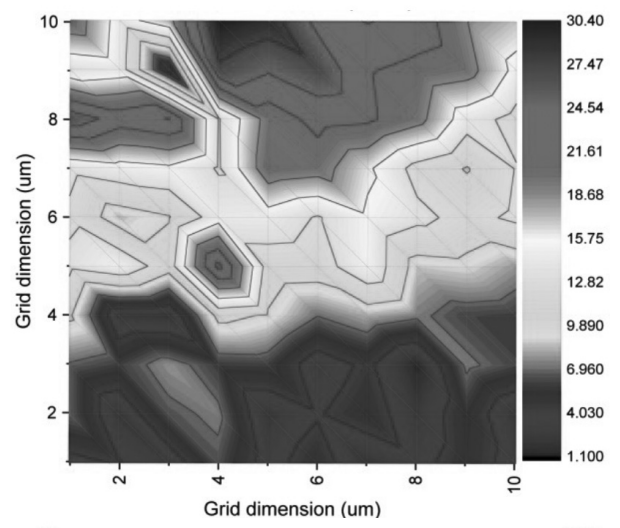

b)

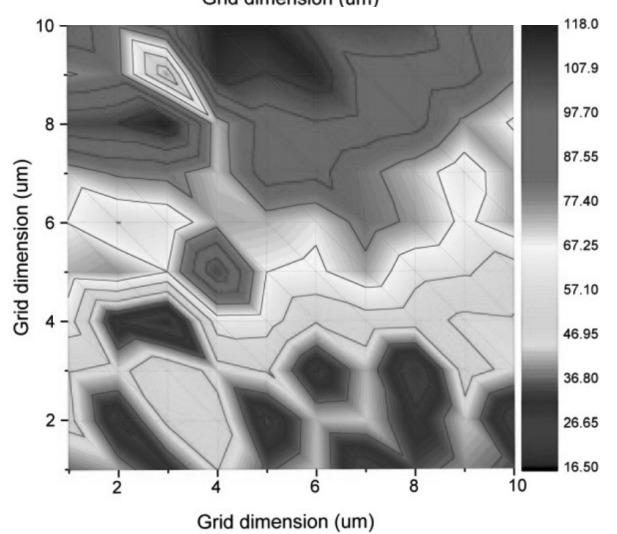

Rys. 6 Rozkład właściwości mechanicznych powłoki $\mathrm{ZrO}_{2}-\mathrm{Y}_{2} \mathrm{O}_{3}$ natryskanej plazmowo z zawiesiny. a) twardość, b) moduł Younga Fig. 6. Distribution of mechanical properties of $\mathrm{ZrO}_{2}-\mathrm{Y}_{2} \mathrm{O}_{3}$ coating plasma sprayed from suspension: a) hardness, b) Young's modulus

Tablica IV. Właściwości mechaniczne powłoki $\mathrm{ZrO}_{2}-\mathrm{Y}_{2} \mathrm{O}_{3}$ natryskanej plazmowo z zawiesiny oraz proszku

Table IV. Mechanical properties of $\mathrm{ZrO}_{2}-\mathrm{Y}_{2} \mathrm{O}_{3}$ coating plasma sprayed from suspension and powder

\begin{tabular}{|c|c|c|c|}
\hline \multicolumn{2}{|c|}{ Zawiesina $\mathrm{ZrO}_{2}-8 \mathrm{Y}_{2} \mathrm{O}_{3}$} & \multicolumn{2}{c|}{ Proszek $\mathrm{ZrO}_{2}-8 \mathrm{Y}_{2} \mathrm{O}_{3}$} \\
\hline $\mathrm{H} \pm \Delta \mathrm{H}(\mathrm{GPa})$ & $\mathrm{Y} \pm \Delta \mathrm{Y}(\mathrm{GPa})$ & $\mathrm{H} \pm \Delta \mathrm{H}(\mathrm{GPa})$ & $\mathrm{Y} \pm \Delta \mathrm{Y}(\mathrm{GPa})$ \\
\hline $8,4 \pm 5,3$ & $99,1 \pm 4,0$ & $10,6 \pm 0,6$ & $96,8 \pm 6,2$ \\
\hline
\end{tabular}

\section{Wnioski}

Na podstawie przeprowadzonych badań można stwierdzić, że metodą natryskiwania plazmowego z zawiesiny wodnej proszku $\mathrm{ZrO}_{2}-8 \mathrm{Y}_{2} \mathrm{O}_{3}$ można otrzymać powłokę o znikomej porowatości, w której nie występują pęknięcia. Mikrostruktura powłok natryskanych plazmowo z zawiesin zawiera nanoziarna i posiada strukturę kolumnową, która różni się od lamelarnej mikrostruktury powłok natryskanych plazmowo z konwencjonalnych proszków. Powłoka natryskana z zawiesin charakteryzuje się znacznie mniejszą średnią arytmetyczną wysokością powierzchni niż w przypadku powłoki natryskanej z proszku konwencjonalnego.

Twardość powłoki natryskanej z zawiesin jest mniejsza niż powłoki natryskanej z konwencjonalnych proszków, ale jej moduł Younga nieznacznie większy.

\section{Literatura}

[1] Pawlowski L.: The science and engineering of thermal spray coatings. J.Willey \& Sons Ltd, Chichester, II ed. 2008.

[2] Handbook Handbook of Thermal Spray Technology ; J.R. Davis, Davis \& Associates, ASM International 2004.

[3] Rampon, R.; Marchand, O.; Filiatre, C.; Bertrand, G. ;Influence of suspension characteristics on coatings microstructure obtained by suspension plasma spraying. Surface \& Coatings Technology vol. 202, Issue: 18, s.4337-4342, 2008.

[4] Xiao, Yanfeng; Song, Lei; Liu, Xiaoguang; Huang, Yi; Huang, Tao; Wu, Yao; Chen, Jiyong; Wu, Fang: Nanostructured bioactive glass-ceramic coatings deposited by the liquid precursor plasma spraying process. Applied Surface Science vol. 257, Issue: 6, s.1898-1905, 2011.
[5] Toma F.-L., Berger L.-M., Naumann T., Langner S.: Characterization of ceramic nanostructured coatings prepared by thermal spraying of suspensions. Proc. of International Thermal Spray Conference Maastricht s.429-434, 2008.

[6] Darut G., Valette S., Montavon G., Ageorges H., Denoirjean A., Fauchais P., Klyatskina E., F. Segova, Salvador M. D.: Comparison of $\mathrm{Al}_{2} \mathrm{O}_{3}$ and $\mathrm{Al}_{2} \mathrm{O}_{3}-\mathrm{TiO}_{2}$ coatings manufactured by aqueous and alcoholic Suspension Plasma Spraying, Proc. of International Thermal Spray Conference, Singapur, s.212-217, 2010.

[7] S. Adamczak, D. Janecki, K. Stępień, Measurement, Cylindricity measurement by the V-block method - Theoretical and practical problems 44 (1) s.164-173, 2011. 